\title{
LA FIGURA DE LA AUTORA EN LA OBRA DE CLARA OBLIGADO: DIÁLOGOS ENTRE SALSA (2002) Y UNA CASA LEJOS DE CASA. LA ESCRITURA EXTRANJERA (2020)
}

\author{
THE FIGURE OF FEMALE AUTHOR IN CLARA OBLIGADO'S LITERATURE: \\ DIALOGUES BETWEEN SALSA (2002) Y UNA CASA LEJOS DE CASA \\ LA ESCRITURA EXTRANJERA (2020)
}

\author{
JaVier IgnaCio Alarcón Bermejo \\ Universidad de Alcalá \\ nachoalarcon2@gmail.com
}

Resumen: El corpus de Clara Obligado posee, a pesar de su amplia diversidad, unas líneas comunes que unen sus distintas obras. Algunos aspectos claves serían: la exploración de temas relacionados con la migración, las reflexiones sobre la identidad, la preocupación por el lugar de las mujeres en la sociedad, la experimentación con la hibridez del lenguaje y una especial preferencia por formas literarias mestizas que cruzan los géneros (combina cuento y novela, ensayo y autobiografía, etc.). Estos elementos, además, dialogan con lo que podemos denominar, siguiendo la teoría de Jérôme Meizoz, la postura autorial de la escritora argentina. Esto constituye una dialéctica compleja entre las ficciones (y demás formas literarias) y la figura de la autora, marcada prominentemente por la cualidad metaficcional y altamente autorreflexiva de las obras. Partiendo de la teoría en torno a la figura de la autora y de un análisis formal y temático de los textos de Obligado, este artículo busca estudiar tales diálogos, centrándose en dos obras: Salsa (2002), una de las novelas claves dentro de la bibliografía de Obligado; y Una casa lejos de casa (2020), un ensayo autobiográfico donde se perfila claramente el posicionamiento de la argentina frente a la escritura y, en general, en el campo literario hispano.

Palabras Clave: Obligado, autorreflexividad, hibridez, autora, identidad

AвSTRACT: Clara Obligado's literature has, despite its diversity, some common trends that link her works. Some of these key characteristics are the exploration 
of themes related to migration, reflections on identity, a concern about women's place in society, a formal experimentation with the hybrid quality of language, and a preference for mix literary genres in her writing (she combines short fiction with novel, essay with autobiography, etc.). These aspects of Obligado's work dialogue with what we can call, following Jérôme Meizoz's theory, the Posture Littéraire or, in other words, the author's stance in the literary field. This builds a complex dialectic between Obligado's fiction and the image she projects as an author. Using the tools provided by different theories about literary authorship and doing an analysis of Obligado's work, this study seeks to understand these dialogues. It focuses on two specific books: Salsa (2002), one of the Argentinian writer's key novel, and Una casa lejos de casa. La escritura extranjera (2020), an autobiographical essay where she clearly reflects about her stance in the Hispanic literary field and about her writing in general.

KeYwords: Obligado, Self-reflexivity, Hybridism, Authorship, Identity

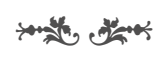

La prosa de Clara Obligado siempre posee una carga de autoconsciencia, incluso cuando no es explícitamente autorreflexiva. Su obra y, sobre todo, sus ficciones hacen tangible el espacio híbrido del que provienen. Este principio adquiere diferentes formas según el caso. Para empezar, vemos una relativa insistencia en la exploración de las distancias lingüísticas que se dan dentro del castellano, según es hablado en una geografía o en otra. La escritora presta atención a los sociolectos e idiolectos que habitan ese espacio común que es el mundo hispano. Por otro lado, son recurrentes, en las narraciones de Obligado, los personajes que se encuentran en tránsito. Términos como "desarraigo" y "diáspora", con la resonancia que pueden tener, poseen una afinidad con la literatura de la autora que trabajaremos a continuación. Ambos aspectos, las personas migrantes y el lenguaje como elemento híbrido, están ligados. Tomando una frase de Una casa lejos de casa. La escritura extranjera (2020), la literatura de Obligado explora el "idioma como frontera, como secreto, como ideología" (2020: 19).

El ensayo autobiográfico del que extraemos este pasaje perfila la postura de la autora y su título da señas claras de hacia dónde apunta. No es solo que sus personajes sean migrantes o que el lenguaje sea, en su prosa, expresión de la hibridez del mundo hispano. La escritora se reconoce como una extranjera, su escritura es reflejo de sus tránsitos por el mundo y, en consecuencia, el manejo del lenguaje en los textos refleja el mestizaje que ella ha experimentado en sus viajes desde su argentina natal hasta el Madrid en el que vive actualmente. La lectura de Una casa lejos de casa afecta la percepción que se tiene de los trabajos previos de Obligado. La voz ensayística, identificada con la autora, reflexiona sobre cómo sus experiencias vitales han definido su forma de pensar y escribir. Dicho de otro modo, el texto revisa los hilos que conectan la vida con la escritura. 
No se debe pensar, a partir de lo dicho, que las ficciones de la argentina son autobiográficas. Por el contrario, el punto de inicio de este análisis es que los vínculos entre la autora y la ficción, al menos en este caso, son complejos. Funcionan en más de una dirección y no se pueden reducir a una interpretación simplista que vea en la persona que escribe el sentido último de los textos. Para explorar esta problemática, resulta necesario revisar sus distintos niveles. Primero, lo que se ha denominado arriba la postura de la autora, un concepto que muestra, en sí mismo, unos matices importantes. Segundo, debemos aproximarnos a las ficciones y ver cómo reflejan las cuestiones planteadas en esta introducción. Dada la amplia bibliografía de la argentina y el espacio limitado que supone un trabajo como este, se restringirá dicha revisión a una obra concreta. Salsa (2003) resulta clave dentro del corpus de la autora y dialoga con su postura autorial, según la podemos perfilar desde Una casa lejos de casa. Un estudio de esta novela permite analizar el vínculo que existe entre ambas instancias, la figura de la autora y los textos que ha firmado.

\section{Escribir sobre la autora Clara Obligado}

Es importante aclarar que, al hablar de la autora, no se apunta necesariamente a la persona concreta que escribe, incluso al usar su nombre. Tal como afirma Michael Foucault en ¿Qué es un autor? (1969), la firma que encabeza un discurso "garantiza una función clasificatoria; un nombre semejante permite reagrupar un determinado número de textos, delimitarlos, excluir algunos, oponerlos a otros" (2010: 20). Luego, el nombre del autor existe en relación con el discurso y lo vincula con otros paratextos y epitextos ${ }^{1}$ que dialogan entre sí. Al mirarlo desde este punto de vista, no sorprende que José-Luis Diaz afirme que los autores son "casi-textos", en tanto que "ya no existen para nosotros más que como textos: sus obras, en primer lugar, donde buscamos su sombra arrastrada, pero también toda una larga perigrafía, hecha de prefacios, confesiones, memorias, biografías, leyendas" (2016: 76).

El párrafo anterior puede llevar a una conclusión errada y hacer pensar que la figura del autor es algo exclusivamente textual. Sin embargo, las dimensiones de esta cuestión son más amplias y articulan con los intrincados procesos de producción cultural. De forma concreta, es posible enlazar el problema del individuo que produce literatura, y de la imagen que existe de él o ella, con lo que Pierre Bourdieu denominó el campo artístico. En palabras del francés: "el ar-

\footnotetext{
1 Para definir los conceptos de peritexto y epitexto, que Gerard Genette se encarga de revisar en profundidad en Seuils (1987), resulta útil retomar las palabras de Phillipe Gasparini: "Je reprendre ici la classification des différents éléments du horstexte qu'a établie Gerard Genette dans son ouvrage fondateur, Seuils, auquel ce chapitre est plus que largement redevable. II y regroupe d'abord, sous l'appellation de 'péritexte', tous les éléments textuels ou iconographiques qui, dans un libre, entourent le texte proprement dit, à savoir: le titre, le sous-titre, les noms de l'auteur et de l'éditeur, le prière d'insérer, la liste des ouvrages du même auteur, la ou les préfaces, l'apparat critique, les illustrations, la dédicace, les épigraphes, les titres de chapitres, les notes, etc. II range d'autre part dans I'épitexte' toutes les informations disponibles sur un livre : critiques et commentaires, études, interviews, autres ouvrages de l'auteur, notoriété, etc. Le paratexte est donc constitué du péritexte et de l'epitexte" (2004: 61).
} 
tista que hace la obra está hecho, a su vez, en el seno del campo de producción, por todo el conjunto de aquellos que contribuyen a 'descubrirlo' y a consagrarlo como artista 'conocido' y reconocido: críticos, prologuistas, marchantes, etc." (2015: 253).

Para entender esta dimensión sociológica de la figura autorial, resulta útil el concepto de "postura de autor", según lo entiende Jérôme Meizoz. En Postures Littéraires. Mises en scène modernes de l'auteur (2007), se explica que las puestas en escena autoriales se construyen a través de una dialéctica entre los posicionamientos individuales y los diálogos que estos establecen con el campo artístico:

C'est toute la difficulté, car l'agir postural se manifeste à la cheville de l'individuel et du collectif : variation individuelle sur une position, la posture ne se rattache pas moins à un répertoire présent dans la mémoire des pratiques littéraires. Le champ littéraire regorge de récits fondateurs, de biographies exemplaires, et tout auteur le devient par référence à de grands ancêtres auxquels il emprunte de croyances, des motifs mais aussi des postures. (Meizoz 2007: 25)

El perfil del autor se edifica de forma dinámica. Es producto de su contexto, el campo literario, y simultáneamente de las acciones de la persona detrás de la imagen, de cómo ella se proyecta.

Los mecanismos que participan en este proceso son diversos. Juegan un papel clave los peritextos y epitextos que rodean una obra, como señalamos al mencionar la teoría de Foucault. En esta línea, es importante tomar en cuenta que los paratextos no se reducen a discursos, literarios o críticos, que se refieran directa o indirectamente a la obra de un escritor o a su persona. Debemos considerar también las fotografías de los autores, sus entrevistas, los premios literarios que han ganado, sus amigos y conocidos dentro del campo, las editoriales que los publican, etc. En resumen, y para decirlo con Bourdieu (2015: 338-339), intervienen los mecanismos de legitimación y promoción del campo artístico. A lo que se debe agregar la dimensión discursiva del autor: su estilo literario, los temas que aborda en su obra, los géneros a los que se dedica, las figuras que reconoce como modélicas.

Para comprender este entramado de elementos culturales que dialogan y constituyen la figura del autor, es imperativo apelar a la noción de ethos. El mismo Meizoz utiliza el término para referir una parte importante de su teoría (2007: 21). Luego, para complementar, podemos referir el estudio de Dominique Maingueneau, "El ethos: un articulador", donde se explica:

El ethos resulta, pues, de una interacción entre diversos factores: el ethos prediscusivo (o "previo") y el ethos discursivo (ethos mostrado), ellos mismos en interacción con los fragmentos del texto en los que el enunciado enfoca su propia enunciación (ethos dicho): directa ("es un amigo el que os habla; "soy un francés como los demás", "os hablo con el corazón en la mano") o indirectamente, por ejemplo, a través de metáforas o de alusiones a otras escenas de palabra. (Maingueneau 2016: 137) 
Se entiende el ethos como un punto de cruce, un elemento articulador, en los términos de Maingueneau, que sintetiza los distintos diálogos textuales y extratextextuales que forman la figura del autor o de la autora.

Tras este inciso sobre teoría del autor, es posible reformular la hipótesis que abre este trabajo. En la sección introductoria, implementamos la noción de postura autorial. En este punto, se puede recontextualizar esta idea desde la propuesta de Meizoz, en diálogo con la noción de ethos. En otras palabras, Clara Obligado ha perfilado, a través de sus ficciones y ensayos, un posicionamiento en el campo literario hispano $y$, de forma concreta, en el peninsular. Esta sería su postura, cuyos elementos serán discutidos más adelante. De momento, podemos repasar los aspectos claves que mencionamos previamente: la exploración de temas relacionados con la migración, las reflexiones sobre la identidad de quienes son extranjeros, la preocupación por el lugar de las mujeres en la sociedad ${ }_{1}^{2}$ la experimentación con la hibridez del lenguaje y una especial preferencia por formas literarias híbridas que cruzan los géneros (combina cuento y novela, ensayo y autobiografía, etc.). Estos elementos se ven reflejados, de forma ejemplar, en Una casa lejos de casa y se vinculan con la novela Salsa. Revisar esta conexión ayudará a entender cómo la literatura de esta autora dialoga con su postura autorial. No solo eso, se podrá entrever cómo la implementación de mecanismos metaficticios contribuye a dicho diálogo.

\section{UN MADRID DEFINIDO POR LA MIGRACIÓN: SALSA}

Si prestamos atención a los aspectos de la postura autorial de Obligado enumerados al cerrar la sección previa, Salsa, publicada en 2002, puede verse como un caso ejemplar dentro del corpus de la escritora. La historia se centra en un bar, Los Bongoseros de Bratislava, en el que coincide un grupo de personajes para bailar música del Caribe. La novela es marcadamente polifónica y fragmentaria. Se estructura a través de breves capítulos, cada uno enfocado en alguno de los protagonistas. En consecuencia, funciona como un rompecabezas, en el que las distintas piezas van edificando la totalidad de una historia amplia y compleja. Describir todos los hilos que forman esta trama y la vida de cada personaje sería demasiado largo para un trabajo como este. Podemos subrayar, sin embargo, algunas de las líneas accionales más importantes.

Salsa inicia con el nacimiento del hijo de Gloria. Ella, que ha engañado a su esposo Julio con un profesor de salsa de origen africano, teme que el niño nazca negro. Si bien la infidelidad no es descubierta, la historia de esta mujer se define por el aburrimiento de la vida de ama de casa y el deseo por volver a acostarse con su amante. Por otro lado, encontramos a Jamaica, que no solo es testigo y, a veces, alcahueta de las vidas y aventuras de los demás personajes, sino que reconstruye su propio pasado a través de un discurso rememorativo. Por supues-

\footnotetext{
2 Uno de los trabajos más interesantes de la autora se centra exclusivamente en esta cuestión: ¿De qué se ríe la Gioconda? O por qué la vida de las mujeres no está en el arte (2006). Más allá, y como se verá reflejado en el análisis de Salsa, sus textos se centran, en repetidas ocasiones, en mujeres que se hayan en conflicto con el mundo en el que viven y los roles que les impone la sociedad.
} 
to, también atraviesa conflictos amorosos propios. Es, además, la dueña de Los Bongoseros de Bratislava. Es en este bar donde Ulises, un senegalés que finge ser cubano, da clases de baile, y donde tuvo el romance con Gloria. De especial interés para nuestro estudio serán, sin embargo, otros tres personajes: Marga, una aspirante a escritora española; Viviana, una argentina que no logra publicar sus novelas; y Felicitas Coliqueo, el fantasma de una mujer que vivió en Latinoamérica durante la colonia. Sobre ellas volveremos más adelante.

En resumen, el local nocturno que hace de eje para la novela busca ser una reproducción en miniatura del Madrid que la novela quiere retratar: hay, por supuesto, algunos españoles, también hay caribeños y africanos, una argentina y un griego. La capital española aparece como un espacio de cruce intercultural. Encontramos en el texto una expresión de la existencia diaspórica según la describe Stuart Hall:

La experiencia de la diáspora, como la propongo aquí, está definida no por una esencia o pureza, sino por el reconocimiento de una heterogeneidad y diversidad necesarias; por una concepción de "identidad" que vive con y a través de la diferencia, y no a pesar de ella; [se define] por la hibridez. Las identidades de la diáspora son aquéllas que están constantemente produciéndose y reproduciéndose de nuevo a través de la transformación y la diferencia. (Hall 2010b: 359-360)

La urbe, en tanto que producto de un mundo globalizado, refleja una fragmentariedad que se distancia de concepciones esencialistas de la identidad. Luego, los personajes de Salsa encarnan un hecho que el mismo Hall describe en otro trabajo: "Es más probable que [el mundo globalizado] produzca, simultáneamente, nuevas identidades 'globales' y nuevas identidades 'locales'" (2010c: 390).

Esta manera de entender la relación de la identidad individual con su espacio geográfico y/o con las distintas nacionalidades responde a una nueva forma de concebir la identidad en general. Siguiendo las teorías desarrolladas durante la segunda mitad del siglo xx, Hall propone alejarse de la lógica de la identidad "como un 'verdadero sí mismo' [self]" (2010a: 339). La consecuencia de este distanciamiento es una concepción del sujeto inestable, fragmentaria y compleja. Dicho de otro modo:

Esto produce el sujeto postmoderno, conceptualizado como carente de una identidad fija, esencial o permanente. La identidad se convierte en una "fiesta móvil", pues es formada y transformada continuamente con relación a los modos en que somos representados o interpelados en los sistemas culturales que nos rodean [...]. Está definida histórica y no biológicamente. El sujeto asume diferentes identidades en momentos distintos, identidades que no están unificadas en torno a un "yo" coherente. Dentro de nosotros coexisten identidades contradictorias que jalan en distintas direcciones, de modo que nuestras identificaciones continuamente están sujetas a cambios. Si sentimos que tenemos una identidad unificada desde el nacimiento hasta la muerte, es sólo porque construimos una historia reconfortante o "narrativa del yo" sobre nosotros mismos. (Hall 2010c: 365) 
Luego, incluso para una persona que pase su vida entera en un mismo país o ciudad, la autopercepción y la construcción de la identidad resultan problemáticas. ${ }^{3} \mathrm{Si}$ sumamos a este panorama la experiencia de la diáspora que comentamos arriba, se revela la complejidad del tema abordado en Salsa.

En el caso de Obligado, y como se puede entrever en Una casa lejos de casa, hay un especial interés por el problema del desarraigo. Así describe la escritora su llegada a España:

La herida al aire libre. La hostilidad contra un país extraño en el que no se quiere estar. La pérdida de la pertenencia. Los ojos en la nuca. Las pesadillas. Pero lo que no imagina quien llega es que la distancia se hace carne. Poco a poco iría fraguando la certeza de que la pérdida de la patria no puede repararse nunca, pero bien puede convertirse en un gran tema literario. (Obligado 2020: 48)

Mientras que Hall analiza la situación de quien emigra desde la teoría, Obligado acerca al lector a la intimidad del exiliado. Subraya el dolor y la situación hostil que experimenta quien llega a un nuevo país (situación agravada, en este caso, por el hecho de que la migración fue forzosa).

Por otro lado, y aunque en distintos puntos de Una casa lejos de casa se comenta la nostalgia por el lugar de las raíces, también se hace énfasis en cómo el sentido de pertenencia se pierde. El desarraigo es, a través de esta óptica, una forma de autoafirmación: "El exilio como identidad. La extranjería como patria. Sin sujetarme a la tierra, como el clavel del aire, enraizar" (2020: 76). Parte clave de esta experiencia es la pérdida de la supuesta identidad original: "Alguien dirá: 'la escritora argentina'. No sé si el adjetivo me define o es una maldición" (2020: 104). La autora explica que la "maldición" proviene del hecho de que se le excluye del campo literario español por ser extranjera. Está ubicada en un espacio indefinido, no es de España ni de Argentina. Se puede inferir cómo esto afecta su postura autorial: Obligado se define a sí misma como una escritora extranjera.

Este aspecto de la vida del extranjero traspasa a Salsa. Cada personaje de la novela es, a su manera, migrante. Incluso los que son españoles poseen una identidad fragmentada y, en cierto sentido, definida por el desarraigo. Sin embargo, se hace énfasis en el margen que habitan quienes provienen de otras geografías. No sorprende, por esto, que el bar que hace de eje para los protagonistas, en lugar de estar decorado con paisajes madrileños, posea un mural que retrata la ciudad de Nueva York: "Manhattan, es decir, ese lejanísimo El Dorado de los inmigrantes, La Meca, una tierra de ensueño fantaseada por todos los latinos que noche tras noche sacudían las ancas, giraban al son de la salsa olvidan-

\footnotetext{
3 Otro autor con el cual confrontar este principio es Gergen: "La saturación social nos proporciona una multiplicidad de lenguajes del yo incoherentes y desvinculados entre sí. Para cada cosa que 'sabemos con certeza' sobre nosotros mismos, se levantan resonancias que dudan y hasta se burlan. Esa fragmentación de las concepciones del yo es consecuencia de la multiplicidad de relaciones también incoherentes y desconectadas, que nos impulsan en mil direcciones distintas, incitándonos a desempeñar una variedad tal de roles que el concepto mismo de 'yo auténtico' dotado de características reconocibles, se esfuma. El yo plenamente saturado deja de ser un yo" (1992: 26)
} 
do que mañana también carecerían de papeles y de trabajo" (2018: 31). Como se puede deducir de este pasaje, Los Bongoseros de Bratislava es frecuentado por extranjeros que, siendo optimistas, aspiran a que "algún alma caritativa los [ayude] a fraguar un reborde de legalidad" (2018: 31). Dicho de otro modo, desean abandonar el margen e insertarse dentro de la norma, si es que esto es posible.

Un corolario de esta forma de entender y reflexionar en torno a la identidad es la relación que existe con concepciones previas del "yo". Explica Hall: "La identidad totalmente unificada, completa, segura y coherente es una fantasía" (2010c: 365). Esta cuestión también se explora en Salsa. De formas diversas, los protagonistas fingen tener una identidad fija y coherente, y ocultan cómo sus historias contradicen esta noción. Algunos ejemplos relevantes serán revisados en la siguiente sección, pero cabe citar, ahora, al personaje Ulises. Como se señaló anteriormente, para ganarse la vida como profesor de baile, este senegalés finge ser cubano. Si bien Hall apunta a una experiencia sutil en su teoría (la forma en que las personas construyen una identidad ficcional para dar sentido), la novela de Obligado hiperboliza dicha experiencia al presentar identidades claramente falsificadas. El objetivo parece ser enfatizar las paradojas y contradicciones de la sociedad contemporánea, que busca afirmar absolutos incluso cuando posee consciencia de que son fantasías. Este es, de hecho, el sentido del título de la novela: "La salsa es una palabra inventada por los que venden música. La salsa no se canta, se come. Eso sí, está el son, la guaracha, el mambo, la rumba, y muchos ritmos más" (2018: 39). El género musical que encabeza esta historia es un producto creado con fines comerciales, pero se nutre de una diversidad subyacente que suele ser ignorada.

\section{TRes naRradoras: la cualidad especular de SALSA}

La temática de la identidad diaspórica no es la única razón por la que Salsa guarda un estrecho vínculo con la postura autorial de Obligado. Esta es una cuestión comúnmente abordada en la obra de la argentina. En cambio, la autorreflexividad es el punto más prominente para entender cómo dialoga esta novela con su autora. Hay dos personajes que escriben: Marga y Viviana. Además, debemos considerar a otro, Felicitas Coliqueo, cuya complejidad resulta clave dentro del discurso.

Centrémonos, para empezar, en las dos primeras. En estas escritoras podemos entrever el carácter especular de la obra. Salsa posee lo que Lucien Dällenbach denominó una mise en abyme de la enunciación, esto es, un elemento intradiegético que refleja la producción del texto:

Así, pues, entenderemos por mise en abyme de la enunciación, 1) la 'presentificación' diegética del productor o del receptor del relato, 2) la puesta en evidencia de la producción o de la recepción como tales, 3) la manifestación del contexto que condiciona (o ha condicionado) tal producción-recepción. (Dällenbach 1991: 95)

En resumen, estos elementos hacen de espejo. Desde el universo representado en la ficción, son capaces de reflejar el mundo extratextual, específicamente, la creación 
literaria. Luego, en tanto que Marga y Viviana son escritoras, reflejan indirectamente la figura de la autora. Con todo, una afirmación de este tipo resulta problemática. Habría que preguntar hasta qué punto los entes ficticios reproducen o reflejan a Obligado, cuestionar si son una "presentificación" diegética del productor del libro. Se debe dilucidar el funcionamiento de la especularidad en Salsa, los niveles de autorreflexividad que posee la novela y cómo estos contribuyen a construir la figura autorial de la escritora argentina.

El punto de partida sería Marga. Ella representa algo que cualquiera que se enfrente a la creación literaria ha experimentado: el estanco creativo, la falta de ideas. En resumen, el miedo ante la página en blanco. Desde sus primeras apariciones, la vemos en ese lugar: incapaz de escribir la primera palabra de una novela que le dará, quizá, reconocimiento en el mundo literario. Las primeras líneas en las que aparece la ubican en este lugar, en torno al cual girará su historia: "Bajo una montaña de papeles sonó el teléfono en casa de Marga, justo en el momento en que la única idea de la jornada impulsaba sus dedos sobre el teclado del ordenador" (2018: 22). Esta imagen, la de una escritora que no logra concretar ni las escasas ideas que tiene, será persistente a lo largo de la trama.

A esta condición, familiar a cualquier escritor, se agrega una forma de conciencia específica del personaje. Marga es un ama de casa, debe cuidar a su familia y, además, trabajar para mantenerla. En sus palabras: "Además de tener una vida social activísima, soy periodista y escritora. Bueno, muy pronto seré escritora. Tengo también dos hijos, ¿sabe?" (2018: 48). El comentario va dirigido a un cirujano plástico: Marga consulta la posibilidad de una intervención que la "rejuvenezca". Llegando a la cuarentena, ella dedicó su vida a un marido que la dejó por una mujer más joven. En pocas palabras, el personaje no solo es escritora, fue esposa de un hombre desconsiderado, es madre de dos hijos a los que debe mantener, y tiene un complejo en torno a su edad y su cuerpo. Dicho de otro modo, está marcado por los roles de género que se le han impuesto, en tanto que mujer, y sufre la discriminación consecuente.

Marga no es el genio perdido en su propio laberinto intelectual, lugar tan común en la literatura, sino que está obligada a vivir en una realidad que la presiona. La situación hace ecos del ensayo de Virginia Woolf, Una habitación propia (1929), en el que, como es bien sabido, se explora cómo las condiciones materiales e ideológicas afectan a las mujeres que escriben o desean hacerlo. Esto incluye, por supuesto, la dificultad que trae el ser madre y escritora, por ejemplo. Al reflexionar sobre las precariedades que experimentan las mujeres, en general, el texto afirma: "Hacer una fortuna y tener trece hijos, ningún ser humano hubiera podido aguantarlo" (Woolf 1986: 33). Marga, aunque no se rinde, es consciente de cómo su entrega a la vida matrimonial, primero, y familiar, después, ha afectado sus posibilidades: "[el marido] se dedicó durante dos años a preparar oposiciones y por eso ella llegó a la profesión tarde y cansada, tuvo que correr como un galgo hasta caer rendida para encontrar un puesto" (Obligado 2018: 29).

En una entrevista, Obligado comenta esta situación como propia: 
Hablaría de la maternidad. Las escritoras que tenemos hijos, que no somos todas, en general priorizamos la crianza de los niños. Es una ocupación doble, o triple. Por un lado, te tienes que mantener, o sea, tienes que trabajar, por otro, escribes, por otro, te ocupas de tus hijos. Yo me sentaba a escuchar a mis hijas en la noche, que era mi tiempo para escribir. No podía tener una habitación propia. Y tampoco puedo decir que no haya tenido nostalgia de eso, de ese lugar que tenía mi bisabuelo: escribir en un espacio cuidado, cerrado, con los niños en silencio. (en Alarcón 2020)

De esta manera, y con todo lo que separa al personaje Marga de la escritora argentina, vemos una línea que las conecta. Ambas, en tanto que mujeres y madres, deben buscar un difícil equilibrio entre su vocación escritural y sus vidas personales. Luego, si bien no se puede afirmar en ningún momento que Marga sea una reproducción intradiegética de Obligado (son diametralmente distintas en personalidad y vida), sí es posible ver una cualidad autorreflexiva en la protagonista de Salsa. Su figura sirve para reflexionar sobre la condición de escritora, condición que, huelga decirlo, también vive la autora de la novela.

Esta situación en la que se encuentra Marga converge en una consciencia específica sobre la relación del cuerpo y la escritura: "Tal vez si fuese un poco más joven..., con unos escotes más pronunciados..., si hiciese dieta... Pero ¿con qué demonios va a llenar doscientas páginas? De pronto, una idea: podría ser algo sobre mujeres, que está de moda" (2018: 28). La relación que este personaje establece entre los moldes estereotípicos de belleza femenina y la creación literaria se explica a través de un tercer elemento: Marga quiere ser famosa $y$, para lograrlo, la sociedad parece exigirle un cuerpo joven. La condición alienada del personaje sale a relucir constantemente, a través de un rencor irracional que dirige a cualquier mujer más joven y supuestamente más bella.

En lo que respecta a la cualidad autorreflexiva, si bien esto se puede alinear con las líneas temáticas propias de Obligado (la preocupación por el lugar de la mujer en la sociedad y el campo literario), se deber insistir en el distanciamiento que hay entre la autora y el personaje. Si queremos buscar a una protagonista que refleje con mayor proximidad a la escritora argentina, debemos centrar la atención en Viviana. Ella es de origen argentino, aunque ha pasado buena parte de su vida en Madrid. Escribe y vive en la capital española. La relevancia de esta protagonista se hace tangible: expresa los puntos que señalamos al iniciar, la hibridez identitaria y lingüística, refleja una condición específica que se puede asociar, al menos en cierto nivel, con Clara Obligado.

Desde la introducción, se ha establecido que Salsa no es una obra autobiográfica. Sin embargo, viendo la cercanía que existe entre Viviana y la autora, cabe preguntar por otro concepto: la autoficción. Aunque existen diferencias manifiestas entre ambas mujeres, la ficticia y la real, también podemos apreciar coincidencias. No son suficientes para justificar una lectura autobiográfica, pero quizá una noción más flexible, que acepte un grado de ficcionalización en el uso de los elementos tomados de la realidad, puede resultar útil para el análisis. Ahora, hablar de autoficción en este caso puede resultar caprichoso, tampoco existen señas intradiegéticas que permitan ligar de forma definitiva a Viviana y a 
la autora de la novela. Esta es la razón por la que es preferible decantarse por la vertiente especular de la teoría autoficcional. Esta modalidad, que encuentra su primera formulación en el libro de Vincent Colonna, Autofiction et autres mythomanies littéraires (2004), se define desde los mecanismos metaficcionales que pueden reflejar, incluso de forma indirecta, la figura del autor. En las palabras del teórico:

Reposant sur un reflet de l'auteur ou du livre dans le libre, cette orientation de la fabulation de soi n'est pas sans rappeler la métaphore du miroir. Le réalisme du texte, sa vraisemblance, y deviennent un élément secondaire, et l'auteur ne se trouve plus forcément au centre du livre; ce peut n'être qu'une silhouette; l'important est qu'il vienne se placer dans un coin de son œuvre, qui réfléchit alors sa présence comme le ferait un miroir. (Colonna 2004: 119)

Específicamente, para lograr el efecto especular, se subraya la mise en abyme, la duplicación intradiegética del texto o de su proceso de creación, y la metalepsis, el quiebre de las fronteras ontológicas del universo ficcional. A través de estos mecanismos metaficticios se produce un espejo para la figura autorial, haciéndola devenir ficción.

Al considerar lo dicho antes sobre la cualidad especular de Salsa, se puede empezar a entrever la relación entre este modo autoficcional y la novela. Tal como explica Dällenbach en El relato especular, la presencia de alguien que escriba en la diégesis siempre acaba por espejear al autor, pues el ente ficticio apunta hacia la función que la figura autorial ocupa en el discurso. El argumento adquiere potencia al considerar lo dicho sobre Viviana: como Obligado, ella es de origen argentino y vive en Madrid. No solo eso: sus textos, aprendemos en la novela, manejan una prosa híbrida que se ubica en un lugar indefinido entre los dos países. En palabras de la protagonista: "cinco años trabajando en este manuscrito y tengo que oír lo que estoy oyendo: allá, que es demasiado argentino; en Argentina, que es demasiado español. Tendré que aceptar la realidad: como escritora, estoy muerta" (2018: 68).

Viviana refleja una problemática que, como hemos insistido, atraviesa Salsa: la manera en que la transculturalidad y el mundo globalizado, tan celebrados en el siglo $\mathrm{xxI}$, suelen transformarse en una barrera, en una forma de marginalización. El personaje encarna esto de manera amplia, pues, cada vez que habla, traduce simultáneamente los sociolectos castellanos que debe utilizar en Madrid a los argentinos que estaba acostumbrada a usar en su país natal. ${ }^{4}$ Podemos constatar que esta es una realidad que Obligado siente propia al leer su reciente ensayo autobiográfico:

Al variar el registro del castellano, quienes escribimos en la península nos vemos obligados a borrar nuestro castellano natal, minoritario en este caso, que

\footnotetext{
${ }^{4}$ Esta es una preocupación constante en los textos de Obligado. Cabe recordar el relato "Lenguas vivas", parte del volumen Otras vidas (2005). En este, la narradora hace humor en torno a las confusiones que se pueden generar al vivir en un lugar donde se habla una variedad distinta del castellano a la propia. También aquí se puede apreciar un reflejo de la autora, en tanto que se hace énfasis en las distancias entre los sociolectos argentinos y los madrileños.
} 
colapsa y tiende a desaparecer bajo la presión de una lengua más fuerte y de un mercado editorial que no suele aceptar otras variaciones que las que incluyen cierto aire de exotismo latinoamericano. (Obligado 2020: 57)

Por supuesto, estas sincronías no son suficientes para leer en Viviana una representación intradiegética de Obligado e interpretarla como un personaje autoficticio de forma completa. En cambio, las herramientas teóricas que proporciona la autoficción especular sirven aquí para ver en el personaje un espejo de la autora. Dicho de otro modo, Viviana no es una reproducción de Obligado, pero sí es un ente autorreflexivo que otorga autoconsciencia metaficcional al texto. Al hacerlo, señala a la figura autorial y la hace partícipe, aunque indirectamente, de la ficción.

Si encontramos en Viviana al personaje más cercano a la escritora argentina, el ente de autorreflexividad de mayor potencia en Salsa, el tercer nombre que citamos al inicio de esta sección, Felicitas Coliqueo, es el que se muestra menos semejante a la escritora argentina. ${ }^{5}$ No solo eso: en tanto que personaje, es quizá el más complejo de la novela. Se presenta, en primera instancia, como el seudónimo con el cual Viviana firma el manuscrito que ningún editor se atreve a publicar dado su cualidad híbrida. En medio de la frustración, la autora ficticia renuncia a esta firma. Lo que inicia como un posicionamiento nominal acaba en un exorcismo. Tras una noche en la que baila con Omara, una recurrente de Los Bongoseros de Bratislava que, además, hace brujería, Viviana experimenta la siguiente escena:

Viviana duerme mal, inquieta, tiene pesadillas, no comprende qué sucedió en el baile, qué se transformó en ella, se levanta varias veces, se moja la cara y se mira en el espejo desde donde un rostro que no parece suyo la observa, se cepilla los dientes para quitarse ese sabor a tierra que le dejó el humo, tose y jura que no volverá a fumar, luego vuelve a dormirse y sueña con Omara en un sueño inquieto y convulso, recién cuando se asoma el sol y una mañana fresca tiembla sobre la ciudad consigue quedarse tranquila, bajo la luz mortecina puede por fin dormir y se levanta ya tarde, se mira en el espejo, tiene un aspecto espantoso, de fantasma, lanza una bocanada de vapor que borronea su imagen y allí escribe con un dedo 'Felicitas Coliqueo', luego con la manga del pijama tacha el nombre, lo olvida, regresa a la cama, intenta dormir y lo hace, ligera, libre al fin. (Obligado 2018: 76)

Entonces, se revela que Felicitas es, de hecho, un fantasma, un espíritu que habitaba el cuerpo de la argentina y que ocupará, a continuación, otro. El nuevo huésped será Omara, la que ayudó a Viviana a liberarse del espíritu. A partir de este punto, la novela retratará episodios en los que el espectro toma posesión de su nuevo cuerpo para relatar su historia.

\footnotetext{
5 Sin embargo, Obligado ha reconocido que siente al personaje del fantasma próximo. En la misma entrevista que citamos previamente, explica: "Ahí está la idea de posesión. Omara es una cubana que vive en Madrid, que, a su vez, es poseída por una argentina en tiempo de la conquista, Felicitas. Y ella cita los poemas de mi bisabuelo, lo cual lleva la historia al realismo más absoluto" (en Alarcón 2020).
} 
Esta es la razón por la que el fantasma resulta pertinente ahora: lo que ella desea es una voz que le permita revelar su historia. Así explica Felicitas a Omara la noche en que toma posesión:

No te pido que claves alfileres en una muñeca de trapo para que alguien sufra dolores, ni que vayas al cementerio y cojas tierra para ponerla en una jícara, ni que escupas aguardiente sobre una tumba, ni te pido que degüelles una gallina negra. Solo te ruego que me prestes tu voz. Necesito tu voz, Omara, estoy atragantada de palabras. (Obligado 2018: 81)

Este es el vínculo que podemos establecer entre Felicitas Coliqueo y las escritoras de las que hemos hablado; ella también es una narradora, incluso si no escribe. Desea contar una historia.

Los elementos sobrenaturales son parte íntegra de la trama de Salsa. Parece previsible en la obra de una autora que afirma, en Una casa lejos de casa, que tras leer a Julio Cortázar y al boom latinoamericano de los 60 "la literatura no volvió a ser realista" (2020: 33). Sin embargo, la implementación de estos hechos aparentemente imposibles no es caprichosa. Dialogan con el tema de la identidad diaspórica y, al hacerlo, complementan la construcción del discurso crítico de la novela. Dicho de otro modo, al explorar las diferentes culturas que transitan y conforman Madrid, considerar creencias no europeas, provenientes de Latinoamérica y de África, es inevitable.

Al encajar estas expresiones culturales en un contexto amplio, el madrileño, se les puede estampar la etiqueta de "mágicas". Sin embargo, el discurso crítico de la novela de Obligado parece apuntar en otra dirección. Da voz a formas culturales que han sido históricamente silenciadas e invisibilizadas, pero que aun así coexisten con los discursos dominantes. En otras palabras, y como se infiere de las historias que cuenta a través del cuerpo de Omara, Felicitas Coliqueo revela una cultura que ha sido oprimida, truncada y explotada, una parte de la humanidad que está "atragantada de palabras". 6

En resumen, el pasado colonial, comúnmente relegado a un discurso distante y ajeno, adquiere forma en una voz-narradora fantasmal que irrumpe en el mundo madrileño de la novela de Obligado. El pasado se hace presente y necesita una voz viva para ser oído. Esto sintetiza otra de las cuestiones centrales de la obra que estudiamos, la forma en que personas provenientes de las excolonias africanas y latinoamericanas son ahora parte íntegra de la capital española.

Es importante matizar esta idea. Felicitas Coliqueo no es el fantasma de una mujer proveniente de las culturas autóctonas de América. Es, en cambio, una rubia española secuestrada por los indígenas. Acaba enamorada del indíge-

\footnotetext{
${ }^{6}$ Este procedimiento no es exclusivo de la obra de Obligado. En un ensayo sobre Beloved (1987), de Toni Morrison, la crítica Barbara Christian comenta cómo la obra norteamericana explora religiosidades africanas. Al hacerlo, adquiere un tono no-mimético que, en occidente, puede leerse desde lo fantástico u otras formas de literatura diferentes a la realista. Pero, argumenta Christian, lo que la novela de Morrison hace es dar voz a la cultura afroamericana que, dado el tráfico de esclavos, fue arrancada de su tierra. En pocas palabras, estos aspectos no-miméticos sirven para reflexionar sobre una cultura truncada por un hecho traumático (Christian 1997: 365-355). Si bien hay importantes diferencias entre Salsa y Beloved, vemos que hay una analogía en esta forme de abordar los elementos no-miméticos.
} 
na americano que la acoge como esposa. Aunque eventualmente regresa a su vida en la "civilización", extraña al hombre que la mantuvo cautiva. El síndrome de Estocolmo posee un punto irónico y sirve para construir un discurso crítico en torno a la situación de la mujer en la colonia (y que no deja de reflejar situaciones actuales). Por un lado, se acentúa cómo las mujeres eran tratadas como mercancía, como botines en los conflictos bélicos. Por otro, el hecho de que Felicitas prefiera vivir con los indígenas americanos interpela la supuesta cualidad civilizada que poseían los europeos que llegaron al llamado "nuevo mundo". Nunca se sugiere, en Salsa, que los secuestradores fueran buenos, en general, o mejores que quienes colonizaban. Sin embargo, la experiencia que narra el fantasma, y su perspectiva sobre lo que ocurrió, muestra cómo la cultura europea tampoco era necesariamente superior.

Hay un último giro de tuerca que debemos considerar. Al escuchar a una Omara posesa relatar historias exóticas a su hija, Marga decide escribir (sin permiso) la historia de Felicitas Coliqueo. La potencia simbólica de este hecho, que la escritora española sin ideas, enfrascada en la enajenación de su propio cuerpo, decida aprovechar las historias olvidadas del fantasma, casi no necesita ser subrayada. El exotismo, una forma clara de opresión e invisibilización, ha sido materia prima de la literatura occidental durante siglos. Aquí adquiere una forma concreta: la escritora española se apropia de la historia de una mujer sin voz.

\section{CONCLUSIÓN}

En "Qué es una autora o qué no es un autor" (2019), Aina Pérez Fontdevila cierra argumentando que es importante entender a las escritoras en situación. Tras analizar las posiciones de las filósofas que sostienen su propuesta, sintetiza con las siguientes palabras:

Desde esta perspectiva, escribir implicaría siempre escribir como, es decir, 'en
referencia a una identidad' o a una posición también construida y, finalmente,
ideal e inocupable. En otras palabras, escribir sería siempre representar, poner
en escena o performar el papel de un autor-autónomo, singular, autogenético,
descorporeizado, etc.- respecto al cual nadie [...] puede tener un lugar más que
paródico en el sentido 'serio' que recoge Agamben, es decir, al lado de, en lugar
de, sin lugar propio. (Pérez Fontdevila 2019: 55)

Salsa, de Clara Obligado, reproduce esta idea en la diégesis. El Autor, como ideal impositivo, transita la novela en distintas formas: en el castellano normativo que excluye a Viviana, en la fama y reconocimiento que busca Marga. Al mismo tiempo, estas escritoras concretas están situadas en una realidad con la que deben dialogar y desde la que constituyen su forma de ser y escribir. Entre otras cosas, el humor de la novela de Obligado, sobre los que habría que profundizar en otro estudio, gira en torno a este principio paródico: las escritoras que aparecen en la diégesis son representaciones irónicas de la idealización de la figura autorial y, también, de sus propias carencias individuales. 
Esta estrategia narrativa otorga autorreflexividad a Salsa. Si bien ningún personaje refleja explícitamente a Obligado, todos perfilan la situación desde la que ella escribe. No solo Viviana, en tanto que escritora de textos híbridos que escapan a la norma lingüística. También Marga, al poseer consciencia sobre cómo su cuerpo de mujer determina su escritura y su lugar en el campo literario. Finalmente, el fantasma de Felicitas Coliqueo es una presencia que pesa sobre todo el mundo hispano, especialmente, en una escritora marcada por la migración, como es el caso que se ha estudiado aquí. De esta manera, sin necesidad de ser una novela autobiográfica, Salsa es una afirmación sobre el lugar de su autora, sobre los cruces culturales e identitarios que la han marcado y que, inevitablemente, traspasan a su escritura. Alineando esto con lo dicho en la primera sección de este trabajo, podemos retomar las nociones de postura autorial y ethos, como puntos donde se articulan estos elementos. No deja de ser significativo que la última publicación hasta la fecha de Obligado, Una casa lejos de casa, explicite el posicionamiento de la escritora frente a la sociedad y al campo literario. De mayor importancia resulta cómo, a pesar de los cambios que ha experimentado su escritura y su posicionamiento de autora, este último libro dialoga con Salsa, publicada dieciocho años antes. En ambos textos se puede ver un discurso crítico y, sobre todo, una posición reflexiva en torno a elementos claves de la sociedad contemporánea, como lo son la diáspora y la identidad fragmentada del mundo posmoderno.

\section{OBRAS CITADAS}

Alarcón, Javier Ignacio y Andreina Salazar (2020). Una escritora extranjera. Entrevista a Clara Obligado, Contrapunto <https://revistacontrapunto.com/una-escritora-extranjera-entrevista-a-clara-obligado/> (13 de marzo de 2021).

Bourdieu, Pierre (2010). Las reglas del arte. Barcelona: Anagrama.

Christian, Barbara (1997). "Fixing Methodologies: Beloved", in Female Subjects in Black and White. Race, Psychoanalysis, Feminism, ed. Elizabeth Abel, Barbara Christian y Helene Moglen. California: University of California Press, 363-369.

Colonna, Vincent (2004). Autofiction \& autres mythomanies littéraires. Auch: Tristam.

Diaz, José-Luis (2016). "Muertes y renacimiento del autor", in Los papeles del autor/a: Marcos teóricos sobre la autoría literaria, ed. Aina Pérez Fontdevila y Meri Torras Francès. Madrid: Arco Libros, 55-77.

Foucault, Michael (2010). ¿Qué es un autor?. Buenos Aires: Ediciones literarias.

Gasparini, Philippe (2004). Est-il je? Roman autobiographie et autofiction. París: Seuil.

Gergen, Kenneth (1992). El yo saturado. Dilemas de identidad en el mundo moderno. Barcelona: Paidós.

Hall, Stuart (2010a). "Identidad cultural y diáspora", in Sin garantías. Trayectorias y problemáticas en estudios culturales. Popayán: Envión editores, 339-348.

Hall, Stuart (2010b). "Identidad cultural y diáspora", in Sin garantías. Trayectorias y problemáticas en estudios culturales. Popayán: Envión editores, 349-361. 
Hall, Stuart (2010c). "La cuestión de la identidad cultural", in Sin garantías. Trayectorias y problemáticas en estudios culturales. Popayán: Envión editores, 363-404.

Maingueneau, Dominique (2016). "El ethos: un articulador", in Los papeles del autor/a: Marcos teóricos sobre la autoría literaria, ed. Aina Pérez Fontdevila y Meri Torras Francès. Madrid: Arco/Libros, 131-154.

Meizoz, Jérôme (2007). Postures Littéraires. Mises en scène modernes de l'auteur. Ginebra: Éditions Slatkine.

Morrison, Toni (2020). Beloved. Barcelona: Debolsillo.

Obligado, Clara (2020). Una casa lejos de casa. La escritura extranjera. Valencia: Ediciones Contrabando.

Obligado, Clara (2018). Salsa. Barcelona: Entre Ambos.

Obligado, Clara (2016). Las otras vidas. Madrid: Páginas de Espuma.

Pérez Fondevila, Aina (2019). "Qué es una autora o que no es un autor", in ¿Qué es una autora? Encrucijadas entre género y autoría, ed. Aina Pérez Fontdevila y Meri Torras Francès. Barcelona: Icaria, 25-59.

Woolf, Virginia (1988). Una habitación propia. Barcelona, Planeta. 